Article

\title{
Nonlinear Variations of Net Primary Productivity and Its Relationship with Climate and Vegetation Phenology, China
}

\author{
Jian Yang ${ }^{1,2}$, Xin Chang Zhang ${ }^{1, *}$, Zhao Hui Luo ${ }^{2}$ and Xi Jun Yu ${ }^{2}$ \\ 1 School of Geography and Planning, Sun Yat-sen University, Guangzhou 510275, China; yangjian@scies.org \\ 2 South China Institute of Environmental Sciences, Ministry of Environmental Protection, Guangzhou 510655, \\ China; luozhaohui@scies.org (Z.H.L.); yuxijun@scies.org (X.J.Y.) \\ * Correspondence: eeszxc@mail.sysu.edu.cn; Tel.: +86-020-8411-5833
}

Received: 8 August 2017; Accepted: 19 September 2017; Published: 25 September 2017

\begin{abstract}
Net primary productivity (NPP) is an important component of the terrestrial carbon cycle. In this study, NPP was estimated based on two models and Moderate Resolution Imaging Spaectroradiometer (MODIS) data. The spatiotemporal patterns of NPP and the correlations with climate factors and vegetation phenology were then analyzed. Our results showed that NPP derived from MODIS performed well in China. Spatially, NPP decreased from the southeast toward the northwest. Temporally, NPP showed a nonlinear increasing trend at a national scale, but the magnitude became slow after 2004. At a regional scale, NPP in Northern China and the Tibetan Plateau showed a nonlinear increasing trend, while the NPP decreased in most areas of Southern China. The decreases in NPP were more than offset by the increases. At the biome level, all vegetation types displayed an increasing trend, except for shrub and evergreen broad forests (EBF). Moreover, a turning point year occurred for all vegetation types, except for EBF. Generally, climatic factors and Length of Season were all positively correlated with the NPP, while the relationships were much more diverse at a regional level. The direct effect of solar radiation on the NPP was larger (0.31) than precipitation (0.25) and temperature (0.07). Our results indicated that China could mitigate climate warming at a regional and/or global scale to some extent during the time period of 2001-2014.
\end{abstract}

Keywords: net primary production; spatiotemporal patterns; climate change; phenology; China

\section{Introduction}

Net primary productivity (NPP) is the net amount of carbon accumulated by plants in a given period, and has been regarded as one of the main components of the carbon cycle [1]. Due to a variety of direct and/or indirect anthropogenic activities (e.g., land clearing and conversion) and nature disturbances (e.g., fire, pests) as well as global and regional climate change, forested ecosystems have undergone substantial changes in cover and have increasingly shown declines in health over recent decades [2,3]. As a sensitive indicator of forest cover, function and health, NPP loss may affect the composition of the atmosphere, fresh water availability, biodiversity [4,5], and the ecological adjusting mechanism of energy supply and distribution [6].

Quantifying the inter-annual variability in NPP and the interactions with climate factors would help us understand the terrestrial carbon dynamics and underlying mechanisms in responses to climate change [7]. Recently, many studies have been undertaken on the spatiotemporal variation of NPP and its relationship with climate factors on global and regional scales using a range of approaches from observational $[2,8,9]$ to a suite of remote sensing based methods [10,11]. However, the NPP results were diverse in trends and magnitudes, even in the same region among models [10,12] due to different inputs. Moderate Resolution Imaging Spaectroradiometer (MODIS) annual NPP products have been 
widely used [13,14]; however, uncertainties from inputs and the algorithm resulted in biases and restrained data use regionally or globally to some extent. For instance, $70-80 \%$ accuracy of MODIS land cover products (MOD12Q1) are an assimilated meteorological dataset, not observed data with coarse spatial resolution, the cloud-contaminated MODIS FPAR/LAI (MOD15A2), and weaknesses in the MOD17 algorithm [15,16]. Therefore, it is essential to compare MODIS derived NPP to other models and/or field observed NPP, especially for China, which encompasses a wide range of ecosystems and climates. In addition, the responses of different ecosystems to different magnitudes of climate change are still far from clear, especially in China [17]. Moreover, few studies [12] have investigated the effect of solar radiation as an integrated surrogate for the effects of both day length and sunlight intensity [18] on vegetation NPP, especially when temperature and precipitation are considered simultaneously. In addition, previous studies have shown that vegetation phenology, an important factor that affects plant productivity, has changed dramatically due to climate changes and anthropogenic interference [19], but only a few studies have explored the effect of phenophase variation on NPP [20]. At present, due to the diversity of the trends and magnitudes of vegetation phenophases at different scales, its effects on NPP are still unclear, especially in China, where the vegetation phenophases are diverse at both the regional and biome levels [19]. Furthermore, a linear regression method has been applied by most studies to analyze NPP trend [10,21] despite the trend always showing a non-linear trend, or has one or more turning points within the time period [22,23]. These limitations and/or gaps have impeded our understanding of the dynamic relationship and consequently researchers may have underestimated future changes in plant productivity and/or the carbon cycle throughout China.

China encompasses a variety of ecosystems and climates. The regional climate ranging from tropical to cold-temperate, and from humid in the south to extremely dry in the northwest [24]. Land cover types are diverse, including a broad range of tropical, temperate and boreal forests, grassland, cropland and desert [25]. In recent decades, China has experienced dramatic changes in climate such as remarkably strong El Niño events [26], the freezing low temperatures in early 2008 [24], and frequent occurrences of severe droughts [27]. Meanwhile, land use and land cover changes have occurred at unprecedented rates due to quick economic development, dramatic urbanization [28], and implementation of several large scale forest plantation programs [29]. These changes have resulted in large variations in China's terrestrial ecosystem productivity and have definitely adjusted the terrestrial carbon cycle in China [30]. However, whether the temporal trend of NPP continuously increased or decreased during the study period is still unclear given the possible changes of climate derivers and anthropogenic activities. Additionally, the correlations between NPP and climate derivers as well as vegetation phenophases in recent decade still remain unclear [31].

Due to climatic variability, topographic complexity, natural ecosystem diversity, and intensive human disturbance, China is becoming one of the most critical and sensitive regions in the global carbon cycle for determining the carbon budget at regional and global scales. Furthermore, it provides a good opportunity to identify the effects of climate change on NPP to forecast the potential biosphere feedback to nature in the climate system.

Therefore, two simple models were applied to estimate NPP and the results accompanied by MODIS derived NPP were all compared with the field observed NPP. Then, the results that showed less biases with the field observed NPP were selected to analyze the vegetation NPP dynamics and its relationship with both climate and vegetation phenology in China. More specifically, the authors aim was to (1) explore which model's result was more accurate, and the quantity of uncertainty of MODIS derived NPP in China; (2) understand the spatial pattern of NPP, and investigate whether the temporal trend of NPP was continuously increasing or decreasing in China for the period 2001-2014 given climate change and anthropogenic activities; and (3) estimate the effects of climatic driving factors and vegetation phenology changes on vegetation NPP. 


\section{Materials and Methods}

\subsection{Study Area}

The study focused only on Mainland China. The climate in China is extremely diverse, ranging from tropical regions in the south to subarctic in the north [11]. Therefore, the whole study area was divided into three sub-regions (Figure S1) according to the climatic regionalization of China [32]: (1) Northern China, with mean annual temperature ranges from $-4{ }^{\circ} \mathrm{C}$ to $14{ }^{\circ} \mathrm{C}$ and total annual precipitation ranges from $200 \mathrm{~mm}$ in the northwest to $1000 \mathrm{~mm}$ in the southeast; (2) Southern China, where mean annual temperature ranges from $14{ }^{\circ} \mathrm{C}$ to $22{ }^{\circ} \mathrm{C}$ and total annual precipitation ranges from 1000 to $2000 \mathrm{~mm}$ [33]; and (3) the Tibetan Plateau, which has been called the Third Pole of the World, with an average altitude close to $4000 \mathrm{~m}$ above sea level, a mean annual temperature ranging from $-5{ }^{\circ} \mathrm{C}$ to $12{ }^{\circ} \mathrm{C}$ and precipitation ranging from $>800 \mathrm{~mm}$ to $<200 \mathrm{~mm}$ [34].

\subsection{Dataset and Data Processing}

\subsubsection{Annual Net Primary Productivity (NPP)}

NPP derived from MODIS from 2001-2014 in China were used (MOD17A3, $1 \mathrm{~km}$ ), which have been further used as an important data source for plant productivity monitoring and assessment [35]. The MODIS annual NPP algorithm relies on the summation of the daily estimation of Gross Primary Productivity (GPP) computed globally minus growth and maintenance respiration [14]. To estimate annual NPP, first, the daily estimates of maintenance respiration for leaves and fine roots are subtracted from the daily GPP values. These daily reduced GPP estimates are then summed for each year, and estimates for annual maintenance respiration of living wood tissue and annual total growth respiration are subsequently subtracted, resulting in annual NPP estimates. Full details of the algorithm in MODIS derived NPP can be found in Reference [14]. However, due to the deficiencies and uncertainty of MODIS derived NPP as above-mentioned, the Miami model and Thornthwaite Memorial model were applied in this study, as they are simple to operate with only a few parameters that were easy to obtain, and have a higher spatial and temporal resolution of climate data in China. Additionally, they have previously been applied in China [11,13]. The Miami model is calculated as follows (Equations (1)-(3)):

$$
\begin{gathered}
N P P_{T, P}=\min \left\{f_{1}(T), f_{2}(P)\right\} \\
f_{1}(T)=\frac{k_{1}}{1+e^{k_{2}-k_{3} \times T}} \\
f_{1}(P)=k_{4} \times\left(1-e^{-k_{5} \times P}\right)
\end{gathered}
$$

where $K_{1}, K_{2}$ and $K_{3}$ in Equation (2) are the temperature response parameters with values of 3000, 1.315 and 0.119 , respectively and $T$ is the annual average temperature $\left({ }^{\circ} \mathrm{C}\right) ; K_{4}$ and $K_{5}$ in Equation (3) are the precipitation response parameters with values of 3000 and 0.000664 , respectively, and $P$ is the annual average precipitation ( $\mathrm{mm})$. The parameters of $K_{i}(i=1,2, \ldots, 5)$ were calculated using the least squares method based on the field testing of NPP, and the relative temperature and precipitation collected at 50 locations scattered across five continents [36].

The Thornthwaite Memorial model is expressed as follows (Equations (4)-(6)):

$$
\begin{gathered}
N P P=3000 \times\left(1-e^{-0.0009695 \times|v-20|}\right) \\
v=\frac{1.05 \times R}{\sqrt{1+\left(1+1.05 \frac{R}{L}\right)^{2}}} \\
L=3000+25 \times T+25 T^{3}
\end{gathered}
$$


where $v$ represents the mean annual actual evapotranspiration $(\mathrm{mm}) ; L$ represents the mean annual evapotranspiration ( $\mathrm{mm}$ ); and $T$ and $R$ represent the mean annual temperature and mean annual precipitation, respectively.

Due to the different inputs and parameters in the three models, all the estimated NPP results were compared with the field observed NPP (Table S1), which was calculated from flux tower data based on the eddy covariance method, a micrometeorological method with high-frequency data collection. This method provides direct measures of net carbon fluxes between vegetated canopies and the atmosphere over short and long timescales with minimal disturbance to the underlying vegetation. The observation data were collected from ChinaFLUX sites [37] directly and indirectly from the literature. High-precision $\mathrm{CO}_{2}$ concentration measurements and surface carbon flux measures, made at eddy covariance measurement sites, can be used to improve and validate the algorithms being used by remote sensing and ecosystem models [38]. The observations almost covered the typical ecosystem types in China. Therefore, observations from carbon flux data were applied as a reference to compare the results from the three models. Sites only having one year, the corresponding yearly data for observations, and three simulated values were used directly; and for sites longer than one year, the corresponding multi-year averaged data were applied. Next, two statistical indicators, namely root mean square error (RMSE), and mean absolute error (MAE), were used to evaluate the performance of each method above-mentioned. The best estimated result was then considered in the following analysis of the NPP relationship with climatic factors and vegetation phenology. The two statistical indicators were calculated as follows (Equations (7) and (8)):

$$
\begin{aligned}
\text { RMSE } & =\sqrt{\frac{\sum_{i=1}^{n}\left(N P P_{i}-N P P^{*}\right)}{n}} \\
\text { MAE } & =\frac{1}{n} \sum_{i=1}^{n}\left|N P P_{i}-N P P^{*}\right|
\end{aligned}
$$

where $N P P_{i}$ is the estimated NPP, NPP* is the field observed NPP; and $n$ is the sample size.

\subsubsection{Climate Data and Phenology Extraction}

Monthly meteorological data from 2001-2014, including temperature, precipitation, and solar radiation, were acquired from the China Meteorological Data Sharing Service System (downloaded from [39]) All meteorological data used in this study were verified by China's Meteorological Information Center (located in Beijing, China) [40], thus false or missing data from some of the stations were eliminated [11]. There are 653 meteorological stations recording temperature and precipitation data (301 in Northern China, 258 in Southern China, and 94 in the Tibetan Plateau), and 99 stations recording solar radiation (50 in Northern China, 38 in Southern China, and 11 in the Tibetan Plateau; Figure S2). The Kriging method was used for the spatial interpolation of climate data across the study area [41].

Vegetation phenology metrics (Start of Season (SOS) and End of Season (EOS) for each year) were extracted using TIMESAT software (which is widely used for simulating vegetation phenology [42,43]) by applying the Savitzky-Golay (S-G) method to generate smooth time-series MODIS EVI data. We adopted an adaptation strength of 2.0, no spike filtering, seasonal parameter of 0.5 , S-G window size of 2, and amplitude season start and end of $20 \%$ to calculate the phenology parameters. Length of Season (LOS) was calculated as the difference between the SOS and EOS values.

\subsubsection{Land Cover Data}

A 1-km spatial resolution land cover product, MOD12Q1, was applied in this study to analyze NPP and its variation across vegetation types. The MOD12Q1 land cover dataset which was extensively applied to monitor land use and land cover change [44], is mainly based on the International Geosphere-Biosphere program (IGBP) classification system that obtains a classification algorithm of 
the decision tree and artificial neural network [45]. The MOD12Q1 land cover classes were further reclassified into seven major land cover classes (Figure S1) in the present study: evergreen needle-leaf forest (ENF), evergreen broadleaf forest (EBF), deciduous needle-leaf forest (DNF), deciduous broadleaf forest (DBF), farmland grassland and meadow (GM), and shrubs. However, the data only reflected the land cover classifications and could not consider changes in land cover that occurred over our study period. It was estimated that vegetation changes might be relatively stable over a short time period of approximately 10 years at a regional or global scale [42].

\subsection{Data Processing}

\subsubsection{Trend Analysis and Turning Point Year Detection}

The trends of NPP during 2001-2014 were calculated at both pixel level and regional level. Due to autocorrelation among the inter-annual time series data, a robust non-parametric Mann-Kendall (M-K) trend analysis [46] was applied. This method did not require the independence and normality of the time series data [47], which has been widely used in trend analysis [19]. Previous studies have reported that the $\mathrm{M}-\mathrm{K}$ test statistic $Z$ was approximately normally distributed when the sample size was $n \geq 8$. A positive or a negative $Z$ value indicated an increasing or a decreasing trend respectively, which were all monotonic [46]. The formulas for the M-K method are described in detail in Reference [46]. In addition, trends of the NPP were tested at a significance level of $\alpha=0.05$.

The Theil-Sen median slope estimator was applied to estimate the rate of change of NPP, which was more appropriate for assessing the rate of change in short or noisy time series [48]. The Theil-Sen median slope was computed as (Equation (9)):

$$
\beta_{i}=\operatorname{Median}\left(\frac{x_{j}-x_{k}}{j-k}\right) \text { for } i=1, \ldots, N
$$

where $x_{j}$ and $x_{k}$ are the data values at times $j$ and $k(j>k)$, respectively.

To detect the timing and magnitude of NPP changes, a linear regression model and a piecewise linear regression model (Equation (10)) were used. This method has been widely used [41,49] as it can detect potential turning points (TPs) in a trend of time-series data. In addition, TP was limited to the years 2004 to 2010 to avoid obtaining a too-short segment before or after the TP [50]. The maximum number of TPs was specified as one given that too many TPs would make the result more complex and thus create more uncertainty in the understanding of NPP trends [23]. The models used were:

$$
Y= \begin{cases}\beta_{1} \times t+\beta_{0}+\varepsilon & (t \leq \alpha) \\ \beta_{1} \times t+\beta_{2} \times(t-\alpha)+\beta_{0}+\varepsilon & (t>\alpha)\end{cases}
$$

where $Y$ is the NPP; $t$ is the year; $\alpha$ is the turning point of the NPP time series; $\beta_{0}$ is the intercept; $\beta_{1}$ is the magnitude of the NPP trend before the TP; $\left(\beta_{1}+\beta_{2}\right)$ is the magnitude of the NPP trend after the $\mathrm{TP} ; \alpha$ is the year of the TP; and $\varepsilon$ is the residual random error.

The two models were then fitted to the NPP time-series data using the least-squares method, and the Akaike Information Criterion (AIC) [51] was used to determine whether the TPs were significant as it provides a means for model selection [41,51]. The AIC values of these two models were calculated as (Equation (11)):

$$
A I C=n \times \log \left(\frac{R S S}{n}\right)+2 k+\frac{2 k(k+1)}{n-k-1}
$$

where RSS is the residual sum of squares for the estimated model; $k$ is the number of parameters; and $n$ is the sample size. 
Finally, $\triangle \mathrm{AIC}$ was defined as the difference of the AIC2 of the piecewise linear regression model (model 2) and the AIC1 of linear regression model (model 1); if the $\triangle$ AIC was less than -2 , then model 2 was significantly preferred [8].

\subsubsection{Correlations Relating Climatic Factors, LOS and NPP}

Partial correlation analysis was used to explore the relationships between NPP and climatic factors (mean annual temperature, annual cumulative precipitation, and annual cumulative solar radiation from 2001-2014) as well as LOS, which excluded the effects of other variables. The significance of the correlation coefficients was tested at a significance level of 0.05 .

To understand the direct and indirect effects of climatic factors, LOS on NPP variation (excluding multi-collinearity between climatic factors and LOS), a structural equation model (SEM) with standardized data was applied to examine the influences of climate and LOS change on NPP variation. The SEM was initiated by including all possible relationships. The least significant relationship was then removed stepwise until all relationships were significant and the fit of the model did not increase further [52]. SEM was conducted by the "sem" $R$ package [53], which was then visualized by the $R$ package "semPlot".

\section{Results}

\subsection{Accuracy Assessment of NPP Estimation}

The accuracy of three modeled NPP results (MODIS derived, the Miami model, and the Thornthwaite Memorial model) were assessed by a comparison with the in situ observations. Validation analysis indicated that the modeled NPP results were all very significantly (Figure $1 ; p<0.01$ ) correlated with the in situ NPP measurements. The $R^{2}$ value for the MODIS derived NPP was 0.39 , which was higher than that of Miami model $\left(R^{2}=0.27\right)$ and the Thornthwaite Memorial model $\left(R^{2}=0.28\right)$. Furthermore, the RMSE and MAE deceased to $0.19 \mathrm{~kg} \mathrm{C} \mathrm{m}^{-2} \mathrm{a}^{-1}$ and $0.14 \mathrm{~kg} \mathrm{C} \mathrm{m}^{-2} \mathrm{a}^{-1}$, respectively for the MODIS NPP data compared to $0.29 \mathrm{~kg} \mathrm{C} \mathrm{m}^{-2} \mathrm{a}^{-1}$ and $0.23 \mathrm{~kg} \mathrm{C} \mathrm{m}^{-2} \mathrm{a}^{-1}$ for the Miami model, as well as $0.31 \mathrm{~kg} \mathrm{C} \mathrm{m}^{-2} \mathrm{a}^{-1}$ and $0.26 \mathrm{~kg} \mathrm{C} \mathrm{m}^{-2} \mathrm{a}^{-1}$ for the Thornthwaite Memorial model, respectively. The results demonstrated that the NPP derived from MODIS had an improved performance of NPP simulation by increasing $R^{2}$ by $46.18 \%$ and $40.46 \%$ when compared with the Miami model and Thornthwaite Memorial models, respectively. In addition, the NPP derived from MODIS decreased the relative RMSE and MAE by $34.01 \%$ and $38.34 \%$, respectively, when compared with the Miami model, and by $39.71 \%$ and $45.88 \%$, respectively, when compared with the Thornthwaite Memorial model.

\subsection{Spatial Pattern of NPP}

The spatial pattern of mean annual NPP derived from MODIS for the period 2001-2014 is shown in Figure 2a. The spatial pattern of annual NPP was uneven, which showed gradients decreasing from the south to the north and from the east to the west. The highest value occurred in Southern China, with values generally higher than $0.6 \mathrm{~kg} \mathrm{C} \mathrm{m}^{-2}$ in most of that area. In contrast, annual NPP was usually lower than $0.2 \mathrm{~kg} \mathrm{C} \mathrm{m}^{-2}$ in the Tibetan Plateau. For the remaining regions, annual NPP ranged between 0.2 and $0.6 \mathrm{~kg} \mathrm{C} \mathrm{m}^{-2}$. The standard deviation (Figure 2b) shows a similar spatial pattern with mean annual NPP. The highest value (more than $0.05 \mathrm{~kg} \mathrm{C} \mathrm{m}^{-2}$ ) was mostly distributed in Southern China. The values in Northern China ranged from $0.02-0.05 \mathrm{~kg} \mathrm{C} \mathrm{m}^{-2}$, with the exception of the northern and eastern parts of Northeast China, which was more than $0.05 \mathrm{~kg} \mathrm{C} \mathrm{m}^{-2}$. The lowest standard deviation value was found in the Tibetan Plateau, with values mostly less than $0.02 \mathrm{~kg} \mathrm{C} \mathrm{m}^{-2}$. 

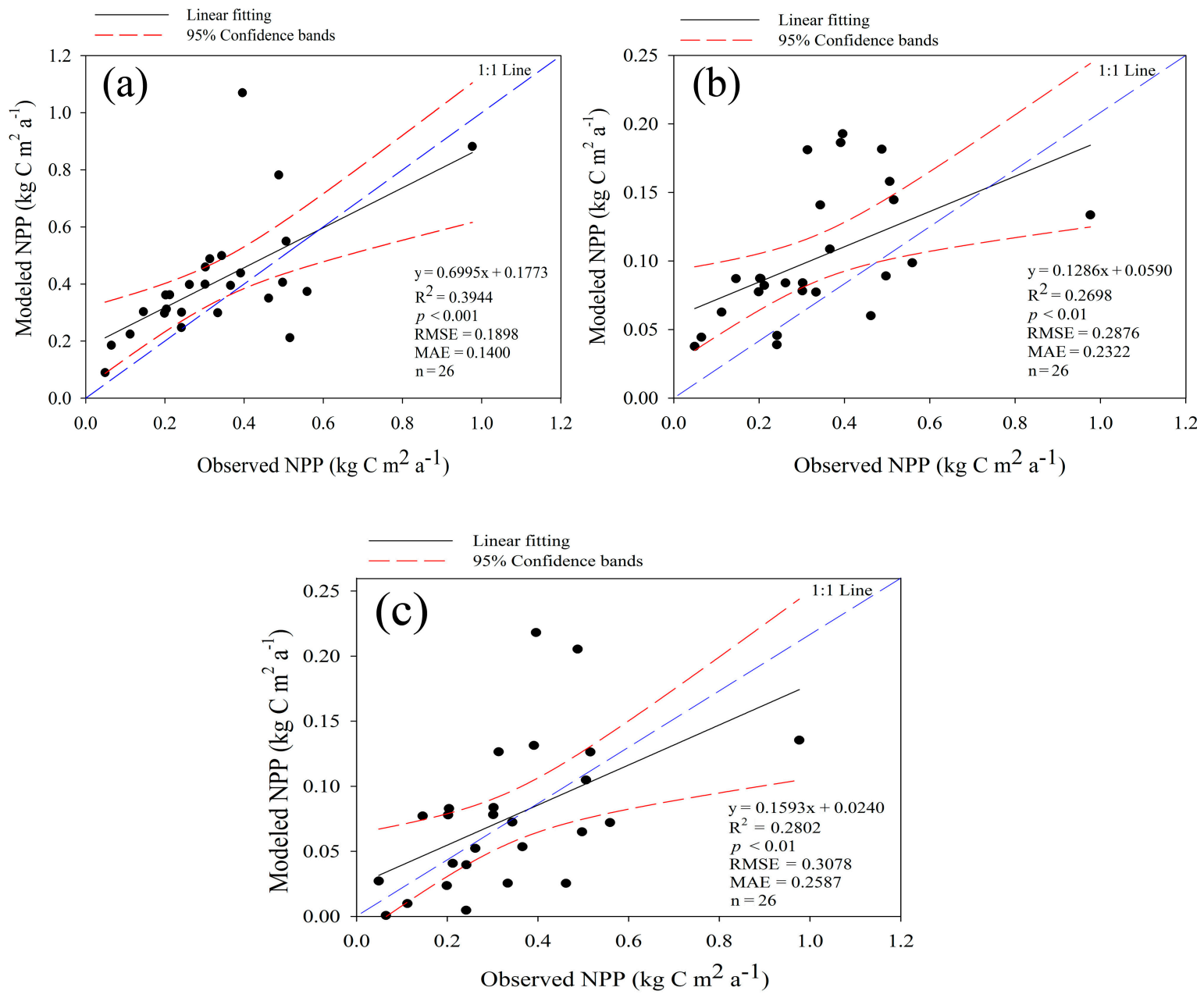

Figure 1. Comparison between the in situ Net Primary Productivity (NPP) site observations and NPP derived from MODIS (a); Miami model (b); and Thornthwaite Memorial model (c).
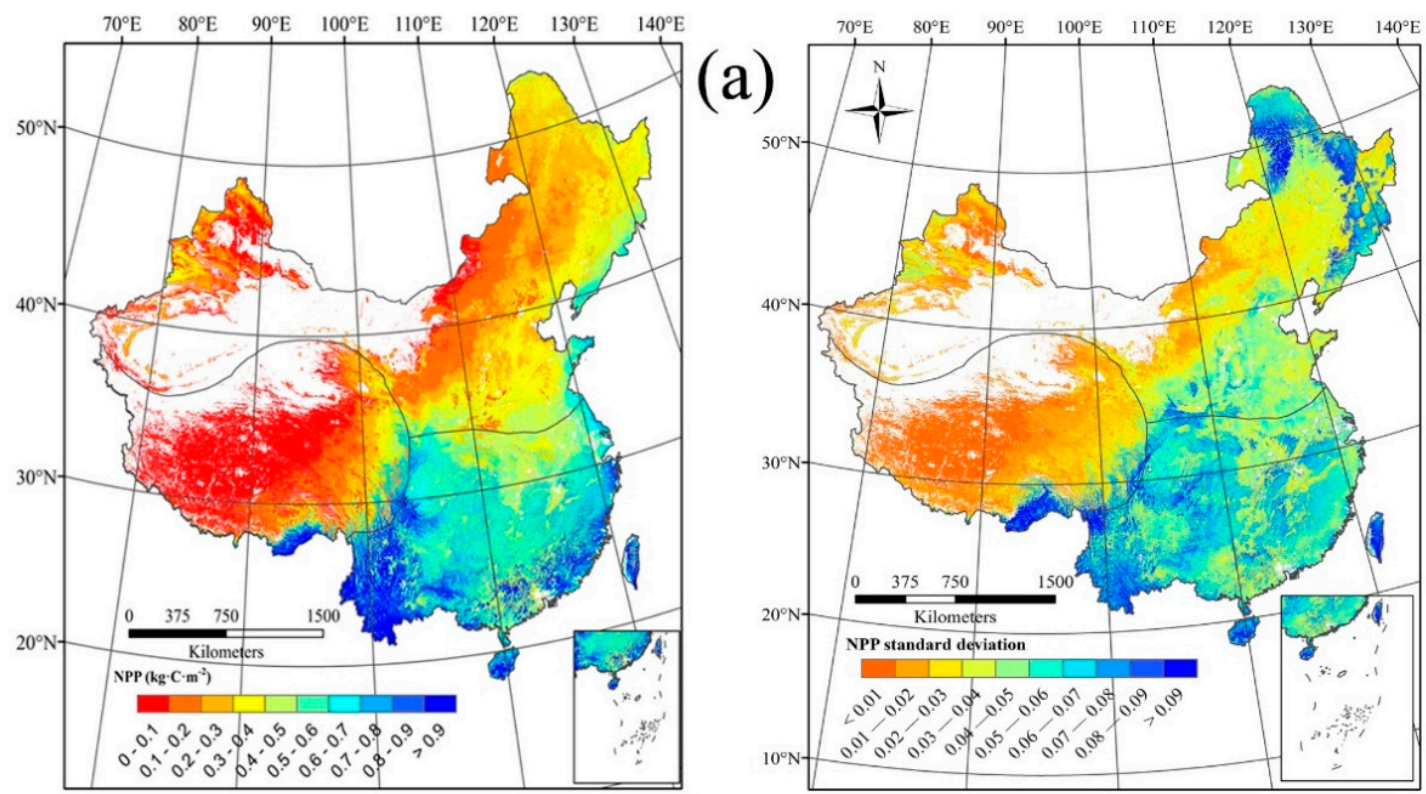

(b)

Figure 2. Spatial distribution of mean Net Primary Productivity (NPP) (a) and standard deviation (b) in China between 2001-2014. 
At the biome level, NPP differs in terms of vegetation types (Figure 3). Generally, forest ecosystems have a higher annual NPP than grassland $(p<0.001)$. Among the forest ecosystems, evergreen forests show a higher NPP than deciduous forests $(p<0.001)$. The highest NPP was found in EBF, with an average annual value of $0.975 \pm 0.362 \mathrm{~kg} \mathrm{C} \mathrm{m}^{-2}$, which was almost twice that of the DBF $\left(0.542 \pm 0.301 \mathrm{~kg} \mathrm{C} \mathrm{m}^{-2}\right)$ and DNF $\left(0.329 \pm 0.103 \mathrm{~kg} \mathrm{C} \mathrm{m}^{-2}\right)$. ENF had the second largest NPP $\left(0.605 \pm 0.277 \mathrm{~kg} \mathrm{C} \mathrm{m}^{-2}\right)$, followed by Farmland $\left(0.422 \pm 0.159 \mathrm{~kg} \mathrm{C} \mathrm{m}^{-2}\right)$ and Shrub $\left(0.317 \pm 0.273 \mathrm{~kg} \mathrm{C} \mathrm{m}^{-2}\right)$, respectively. Grassland had the lowest annual NPP, with an average value of $0.162 \pm 0.196 \mathrm{~kg} \mathrm{C} \mathrm{m}^{-2}$.

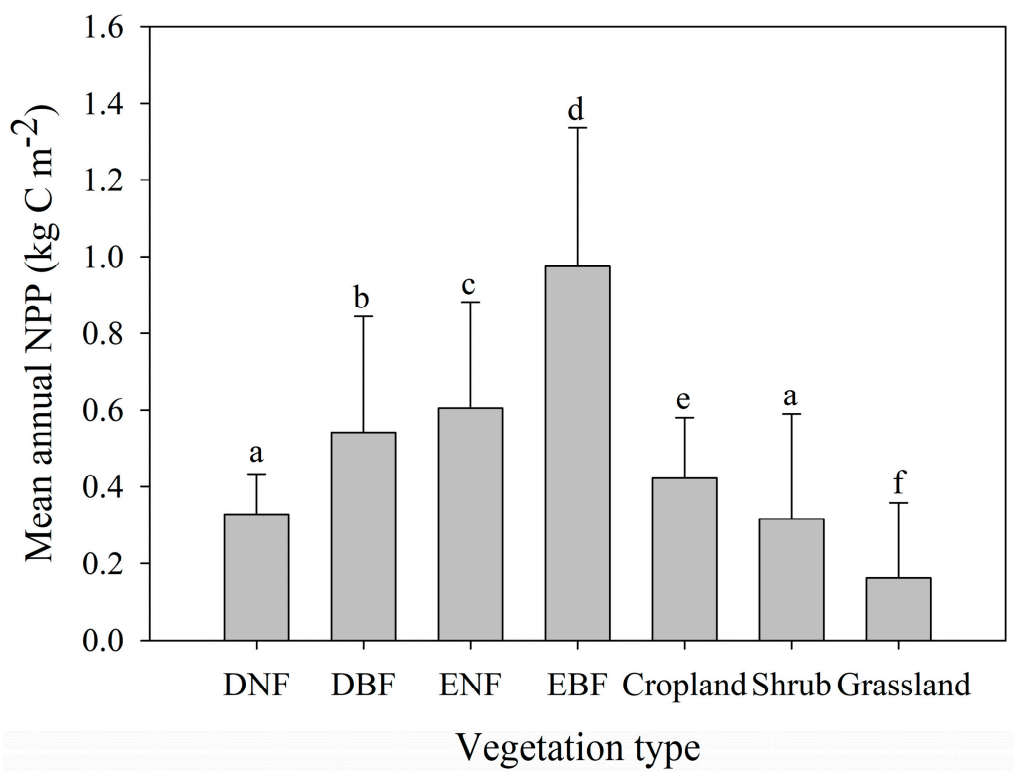

Figure 3. Mean annual Net Primary Productivity (NPP) for each vegetation type over 2001-2014. The error bar in each column indicates the standard deviation. Different lowercase letters indicate significant differences in NPP among vegetation types (one-way ANOVA and $t$-test, $p<0.001$ ).

\subsection{Temporal Trend of NPP}

Figure 4 details the temporal trends in annual NPP across China. Over a 14-year period (2001-2014), $17.69 \%$ of total pixels displayed either significantly increased or decreased trends (Figure $4 b ; p<0.05$ ) in the whole study region. Pixels with a positive (i.e., increased NPP) trend in NPP accounted for $78.94 \%$ of the total pixels, and $15.18 \%$ of the total pixels exhibited a significantly positive trend (Figure $4 \mathrm{~b}, \mathrm{c} ; p<0.05$ ). The increasing rate of NPP in China mainly occurred between 0 and $0.4 \times 10^{-2} \mathrm{~kg} \mathrm{C} \mathrm{m}^{-2} \mathrm{a}^{-1}$ (Figure $4 \mathrm{c}$ ). At a regional scale, $79.15 \%$ of the total pixels showed a positive trend in Northern China, and the increasing rate was mostly distributed in $0-0.6 \times 10^{-2} \mathrm{~kg} \mathrm{C} \mathrm{m}^{-2} \mathrm{a}^{-1}$ (Figure $4 \mathrm{~d}$ ). Similarly, $88.12 \%$ of the total pixels displayed an increasing trend in the Tibetan Plateau, where an increasing magnitude mostly occurred at $0-0.4 \times 10^{-2} \mathrm{~kg} \mathrm{C} \mathrm{m}^{-2} \mathrm{a}^{-1}$ (Figure $4 \mathrm{f}$ ). In contrast, negative trends occurred in $57.64 \%$ of the total pixels in Southern China, with an absolute magnitude mainly ranging from $0.2 \times 10^{-2} \mathrm{~kg} \mathrm{C} \mathrm{m}^{-2} \mathrm{a}^{-1}$ to $0.8 \times 10^{-2} \mathrm{~kg} \mathrm{C} \mathrm{m}^{-2} \mathrm{a}^{-1}$ (Figure 4e). 


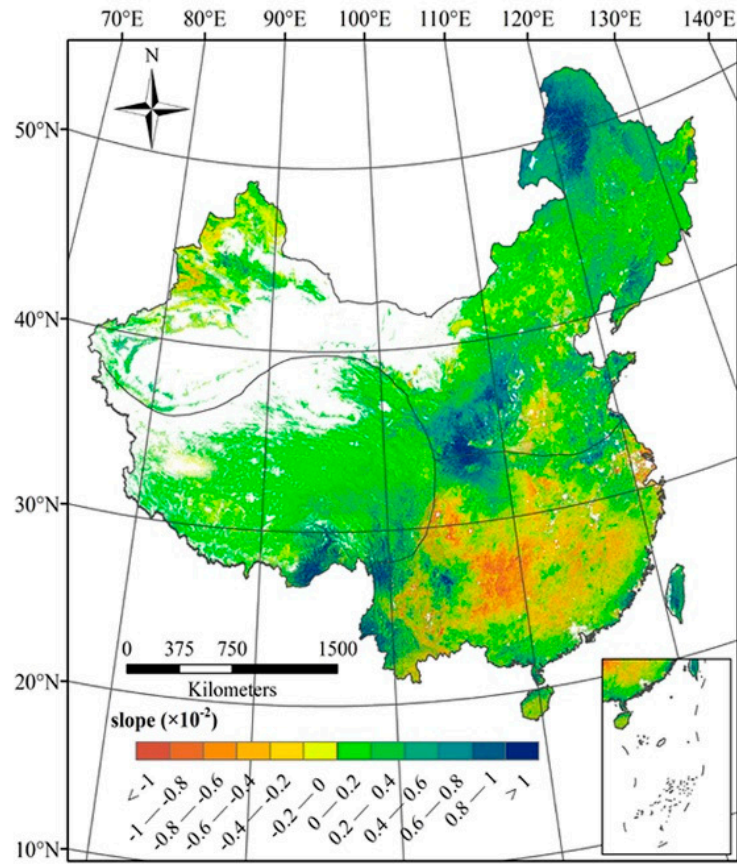

(a)
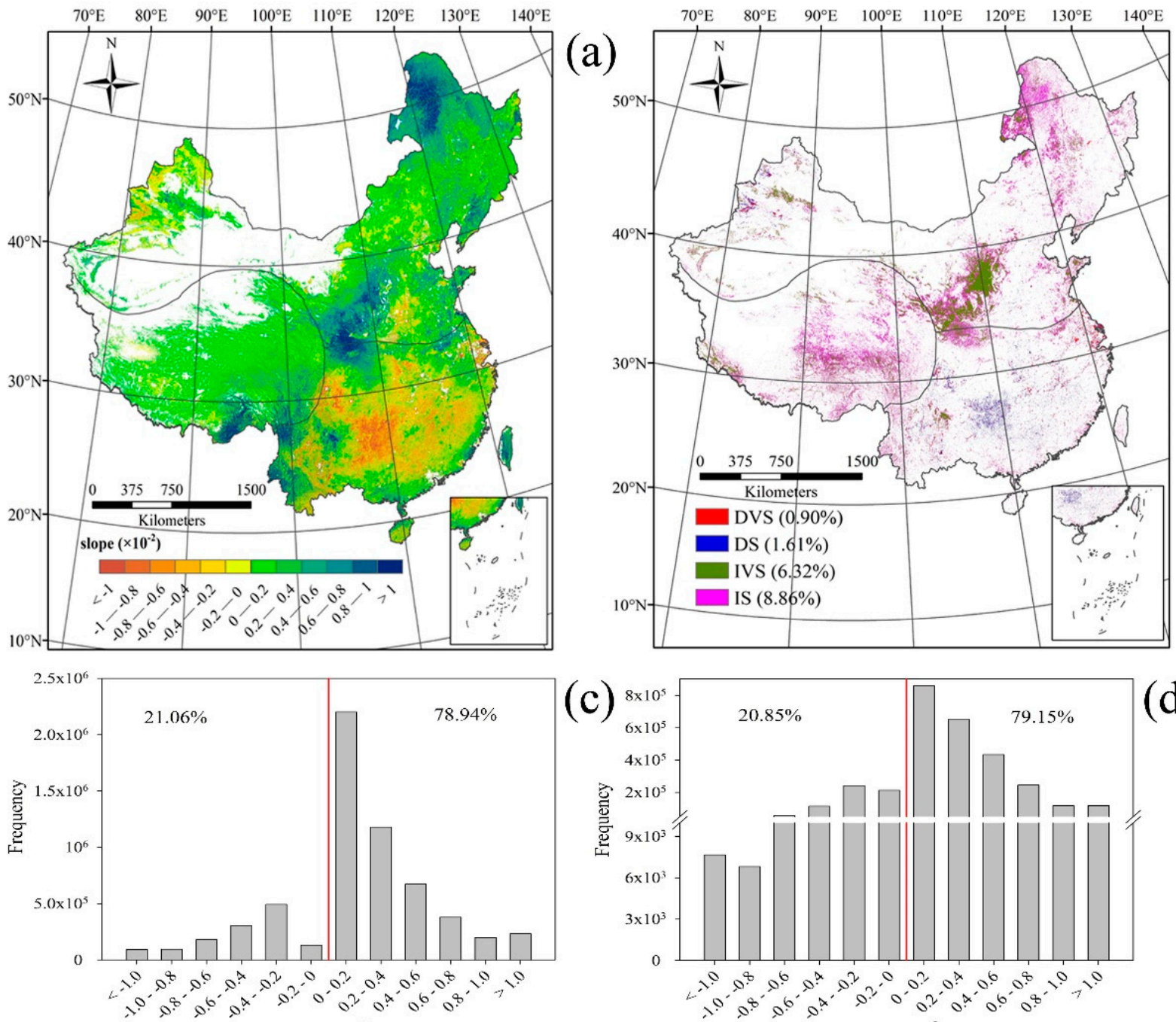

Slope $\left(\times 10^{-2}\right)$

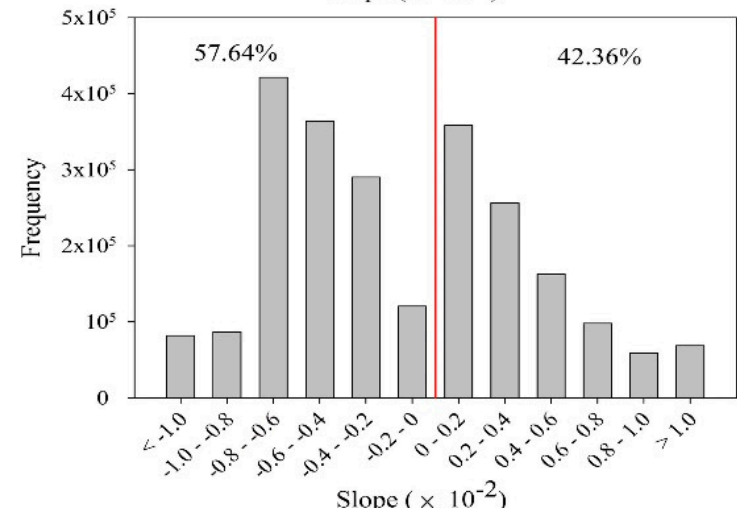

(b)

(c)

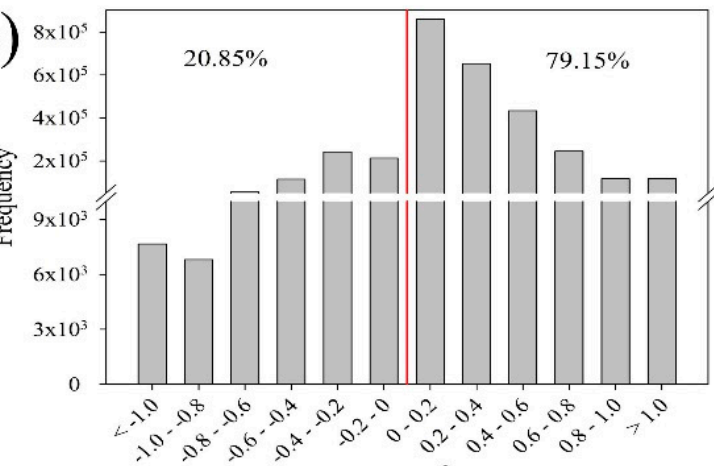

Slope $\left(\times 10^{-2}\right)$

(e)

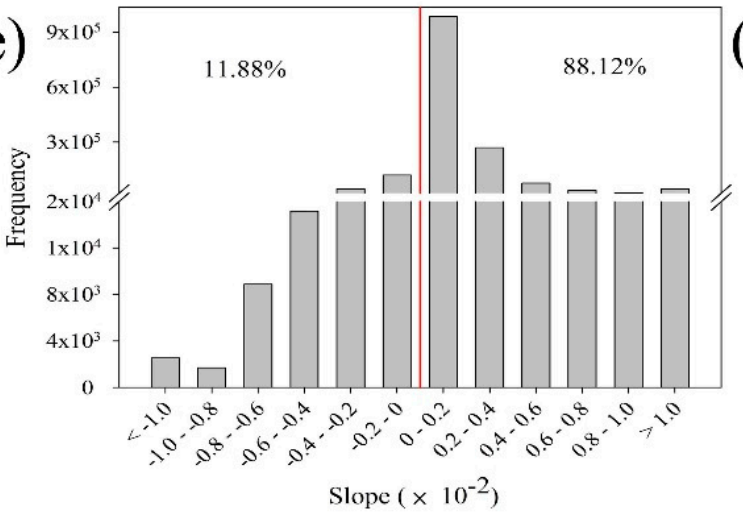

Figure 4. Trends in annual Net Primary Productivity (NPP) within China between 2001 and 2014 (a); and pixels with significant $(p<0.05)$ and very significant $(p<0.01)$ trends are shown in $(\mathbf{b})$. The count distributions of NPP trends in China (c); Northern China (d); Southern China (e) and the Tibetan Plateau (f) are also shown. A positive trend indicated an increase in NPP and vice versa; DS and DVS represent decreased significantly and very significantly, respectively; and IS and IVS represent increased significantly and very significantly, respectively. The red lines in figures (c), (d), (e) and (f) represent boundary for negative slop and positive slop. 


\subsection{Turning Point Year of NPP}

\subsubsection{Turning Point Year of NPP at National and Regional Scale}

To clarify the characteristics of the NPP trends, the averaged trends of the NPP and the turning point year at national and regional levels were calculated over the study period (Figure 5). At the pixel scale, $87.26 \%$ of the total pixels showed abrupt changes in inter-annual NPP variation $(\triangle \mathrm{AIC}<-2$; Figure S3b), most of which appeared at year 2004 or year 2010 (which may also have been caused by criterion we set up in the calculation), accounting for $29.36 \%$ and $31.78 \%$, respectively (Figure S3a). At a national scale, the linear regression model suggested an increasing trend of $0.0007 \mathrm{~kg} \mathrm{C} \mathrm{m}^{-2} \mathrm{a}^{-1}$ ( $p=0.3118$ ) from 2001 to 2014 (Figure 5a). However, two distinct periods were clearly identified by the piecewise linear regression model: a trend change from a marginal significant increasing trend of 0.0104 $\mathrm{kg} \mathrm{C} \mathrm{m}{ }^{-2} \mathrm{a}^{-1}(p=0.0746)$ before 2004 to a non-significant increasing trend of $0.0012 \mathrm{~kg} \mathrm{C} \mathrm{m}^{-2} \mathrm{a}^{-1}$ $(p=0.2775)$ after 2004 (Figure 5a). The information criterion of the piecewise regression model was less than that of the linear regression model $(\triangle \mathrm{AIC}=-3.1797)$. At a regional scale, a marginal significant increasing trend of $0.0025 \mathrm{~kg} \mathrm{C} \mathrm{m}^{-2} \mathrm{a}^{-1}(p=0.0509)$ in Northern China was found, and the turning point year occurred in $2010(\triangle \mathrm{AIC}<-2)$. However, the increasing trends were all non-significant before and after 2010, with a rate of 0.0006 and $0.0068 \mathrm{~kg} \mathrm{C} \mathrm{m}^{-2} \mathrm{a}^{-1}$, respectively (Figure 5b). In Southern China, a rate of $-0.0007 \mathrm{~kg} \mathrm{C} \mathrm{m}^{-2} \mathrm{a}^{-1}(p=0.6559)$ was found for annual NPP variation, and a turning point year occurred in 2010 ( $\triangle \mathrm{AIC}<-2$ ). However, the variation trend was opposite (Figure $5 c)$. Although a significant increasing trend of $0.0016 \mathrm{~kg} \mathrm{C} \mathrm{m}^{-2} \mathrm{a}^{-1}(p<0.01)$ was found in the Tibetan Plateau over the past 14 years (Figure 5d), the increasing trend slowed down after $2006(\triangle \mathrm{AIC}<-2)$.
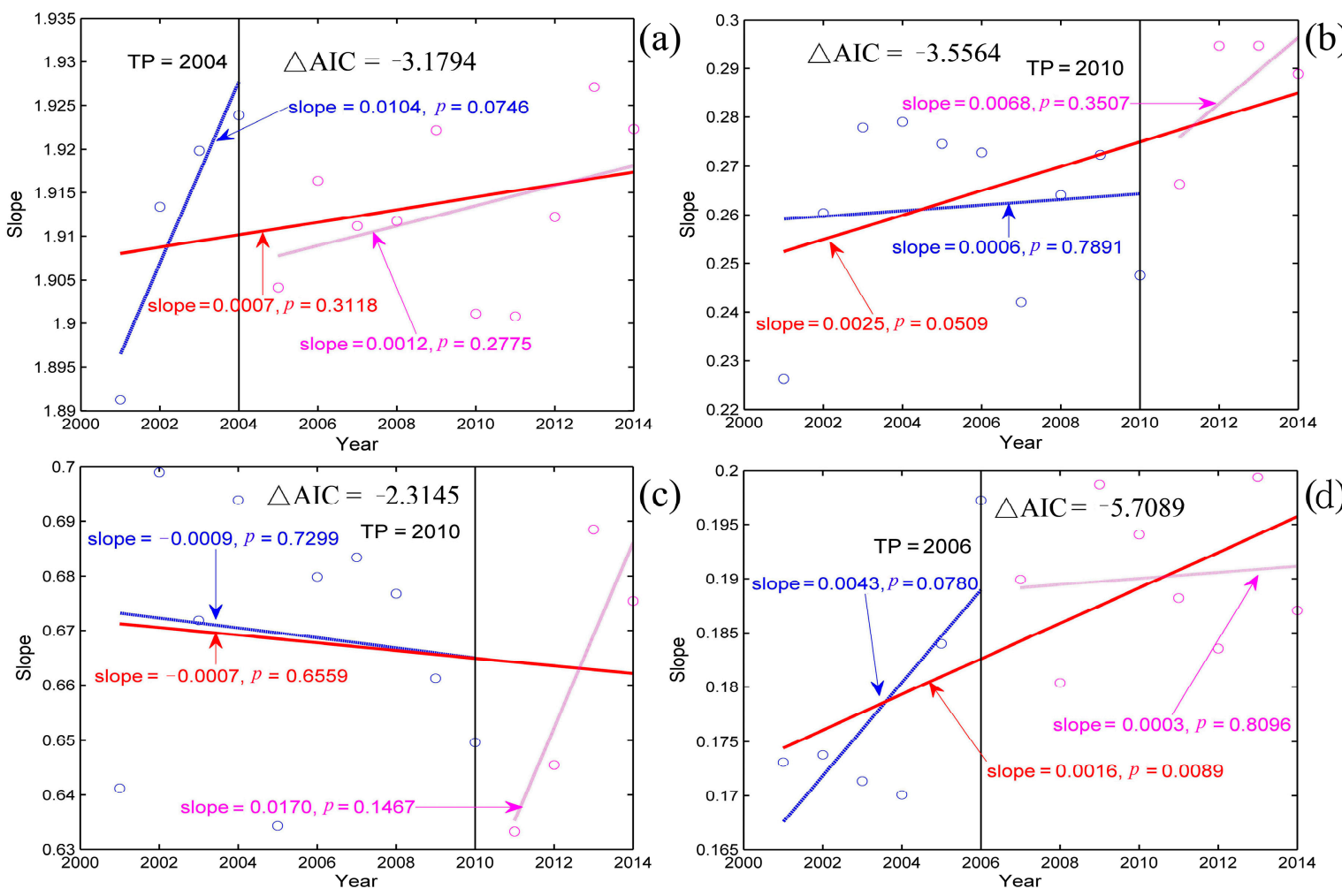

Figure 5. Inter-annual variations of Net Primary Productivity (NPP) in China at national level (a) and regional level (Northern China (b); Southern China (c); and the Tibetan Plateau (d)). Trends estimated by the least-squares linear regression are shown. The blue and pink lines indicate the linear fit before and after the turning year, respectively. The red line indicates linear fit during the period 2001-2014. $\mathrm{TP}$ represents the turning point year. 


\subsubsection{Turning Point Year of NPP at Biome Scale}

At the biome level, the variation of NPP was diverse (Figure 6). All vegetation types had two clearly distinct periods over the study period $(\triangle \mathrm{AIC}<-2)$, with the exception of the EBF $(\triangle \mathrm{AIC}=-1.9314)$ which only showed a non-significant decreasing trend of $-0.0001 \mathrm{~kg} \mathrm{C} \mathrm{m}^{-2} \mathrm{a}^{-1}$ $(p=0.9314)$ during 2001-2014. Farmland and grassland all increased, with a rate of $0.0011 \mathrm{~kg} \mathrm{C} \mathrm{m}^{-2} \mathrm{a}^{-1}$ $(p=0.3734)$ and $0.0016 \mathrm{~kg} \mathrm{C} \mathrm{m}^{-2} \mathrm{a}^{-1}(p<0.01)$, respectively. In addition, the increasing trend before 2004 was larger than that after 2004 for both farmland and grassland. An increasing trend of NPP was found for DNF, ENF, and DBF, but the opposite trend was found for shrub, despite a turning point year occurring in 2010 (all $\triangle \mathrm{AIC}<-2$ and may also have been caused by the criterion we set up in the calculation) for all above vegetation types. In addition, a decreasing NPP occurred for ENF, DBF and shrub during 2001-2010, while an increasing NPP occurred for DNF during the same time period. After 2010, the trend of these four vegetation types was all positive, despite the existence of different magnitudes.
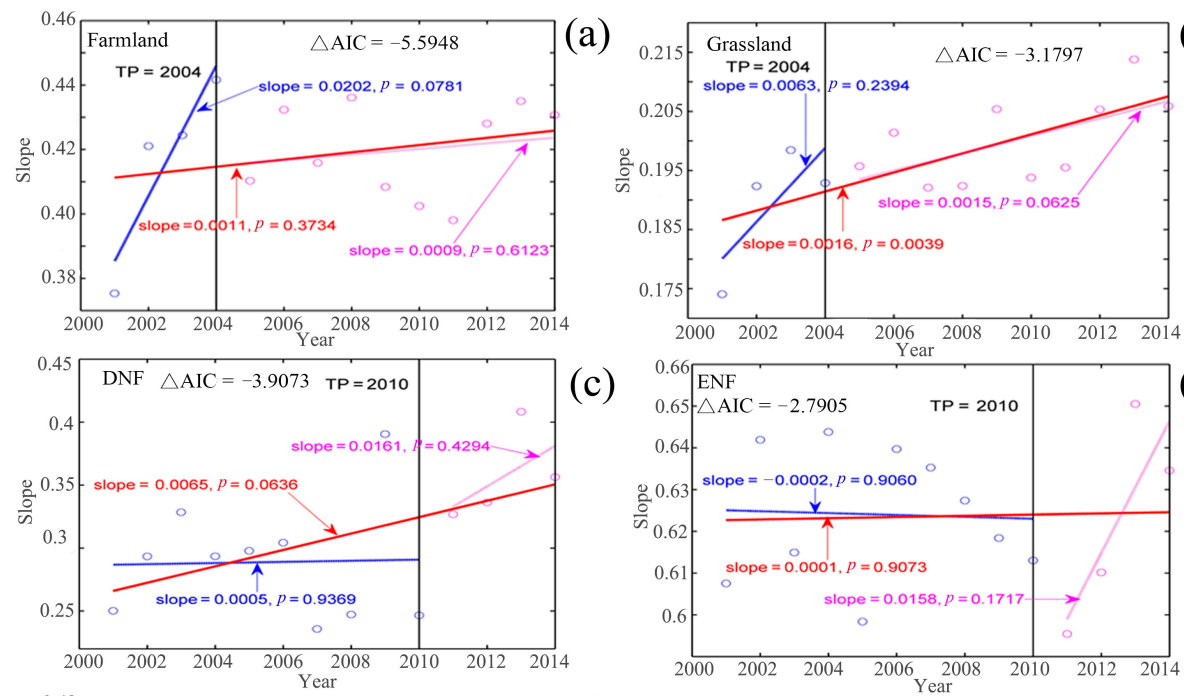

(c)
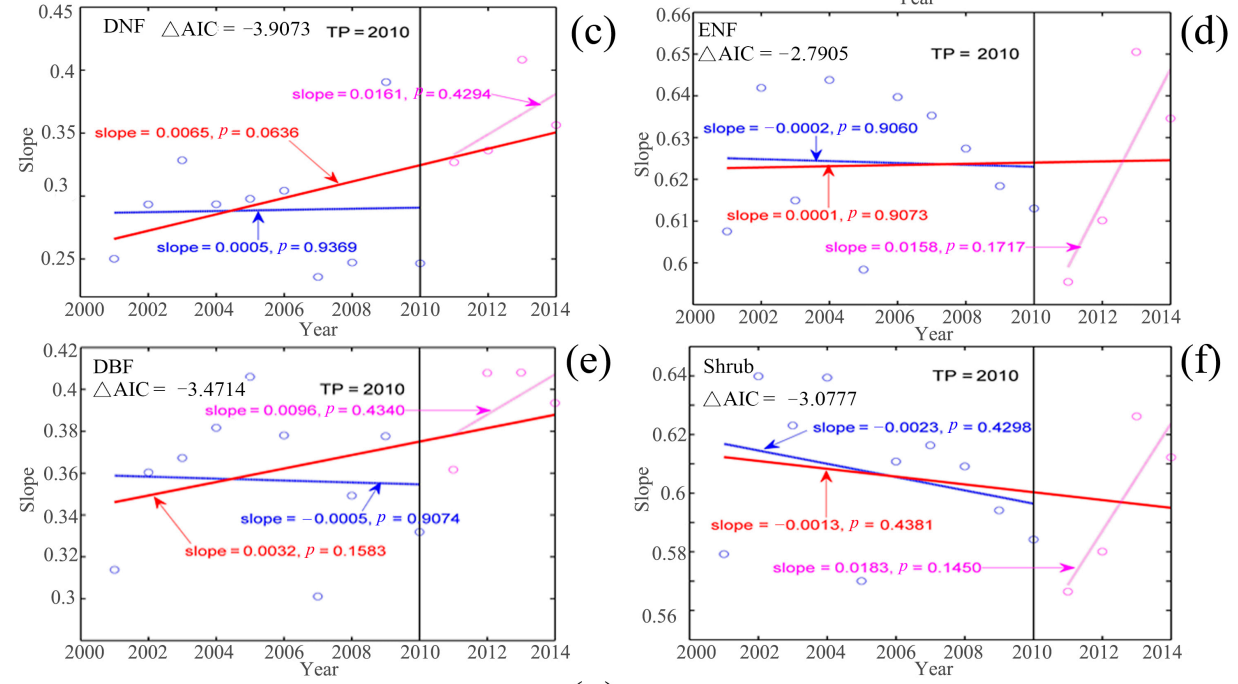

(e)

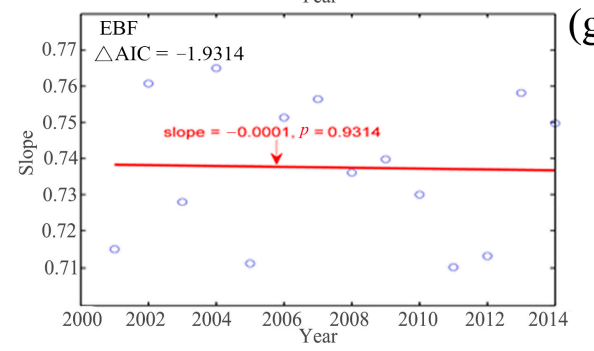

$(\mathrm{g})$

Figure 6. Inter-annual variations of Net Primary Productivity (NPP) in China at the biome level (Farmland (a), Grassland (b), Deciduous needle-leaf forest (c), Evergreen needle-leaf forest (d), Deciduous broadleaf forest (e), Shrub (f), and Evergreen broadleaf forest (g)). Trends estimated by the least-squares linear regression are shown. The blue and pink lines indicate the linear fit before and after the turning year, respectively. The red line indicates linear fit during the period 2001-2014. TP represents the turning point year. 


\subsection{Relationship Relating Climatic Factors, LOS and NPP}

\subsubsection{Correlation Analysis}

Climatic factors were generally positively correlated with NPP on a national scale (Figure 7). Positive partial correlations were observed for $62.66 \%, 70.79 \%$ and $57.60 \%$ of the total pixels with temperature, precipitation, and solar radiation, respectively. The positive correlation coefficients for the climatic variables ranged from $0.1-0.7$. About $56.23 \%$ of the total pixels showed positive partial correlations between NPP and LOS, and the positive partial correlation coefficient was mostly distributed between 0.1 and 0.5 .

At a regional level, $62.97 \%$ of the total pixels in Northern China displayed a negative relationship between NPP and temperature, while precipitation, solar radiation and LOS all generally showed a positive relationship with the NPP (Table 1). Over $57 \%$ of the total pixels in Southern China indicated a positive relationship between the NPP and climatic factors as well as LOS. However, the relationship in the Tibetan Plateau was diverse. Specifically, over $83 \%$ of the total pixels for temperature and about $58 \%$ of the total pixels for precipitation displayed a positive relationship with the NPP, while in general, an opposite relationship occurred between the NPP and solar radiation. In addition, the relationship between the NPP and LOS in the Tibetan Plateau was ambiguous.

Table 1. Partial correlation between the Net Primary Productivity (NPP) and climatic factors as well as Length of Season (LOS).

\begin{tabular}{ccccc}
\hline Variable & Relationship & Northern China & Southern China & The Tibetan Plateau \\
\hline \multirow{2}{*}{ Temperature } & + & $37.03 \%$ & $67.56 \%$ & $83.14 \%$ \\
& - & $62.97 \%$ & $32.44 \%$ & $16.86 \%$ \\
\hline \multirow{2}{*}{ Precipitation } & + & $84.55 \%$ & $62.04 \%$ & $57.83 \%$ \\
& - & $15.55 \%$ & $37.96 \%$ & $42.17 \%$ \\
\hline \multirow{2}{*}{ Solar } & + & $66.93 \%$ & $61.06 \%$ & $34.75 \%$ \\
radiation & - & $33.07 \%$ & $38.94 \%$ & $65.25 \%$ \\
\hline \multirow{2}{*}{ LOS } & + & $57.83 \%$ & $57.56 \%$ & $50.73 \%$ \\
& - & $42.17 \%$ & $42.14 \%$ & $49.27 \%$ \\
\hline
\end{tabular}

+ Represent positive relationship; - Represent negative relationship. 

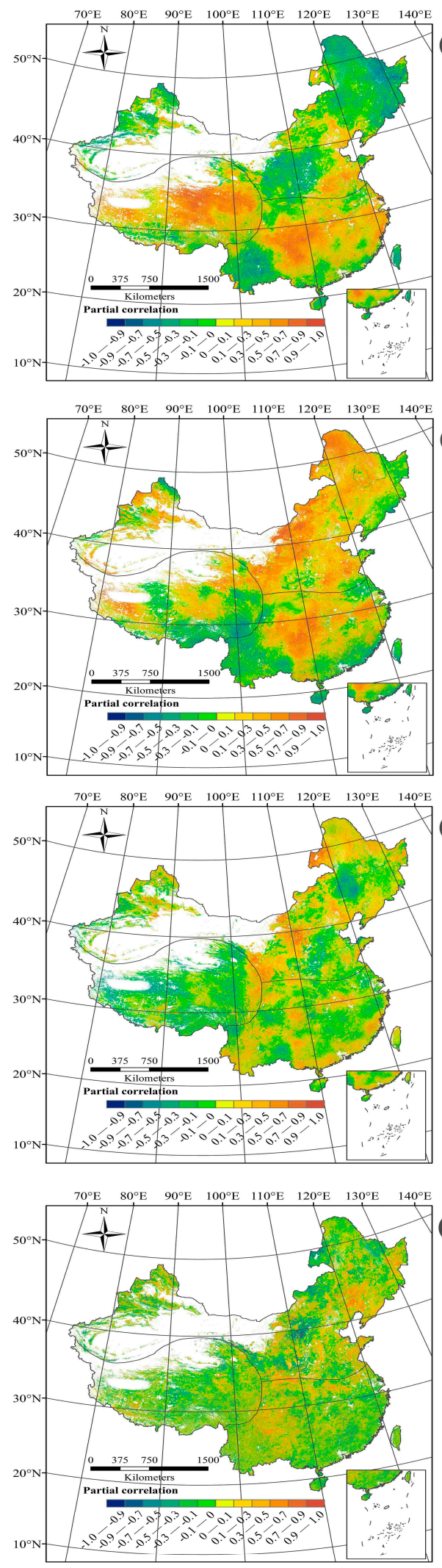

(a)

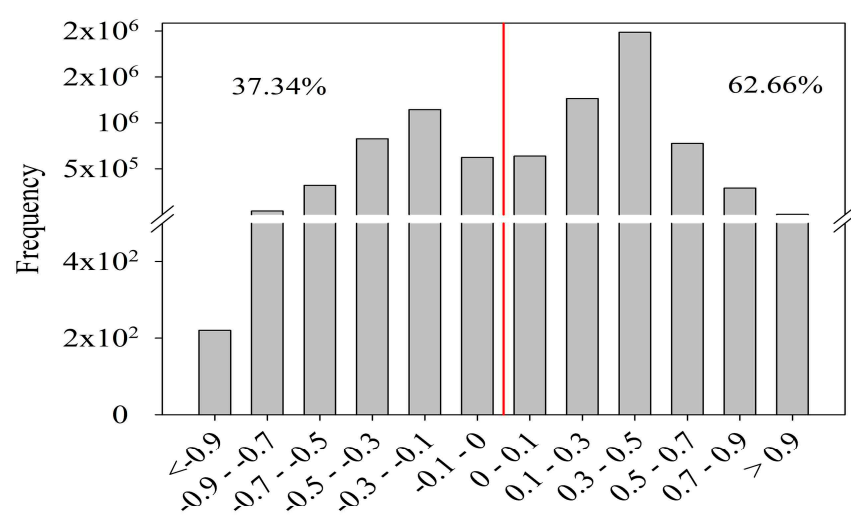

(b)
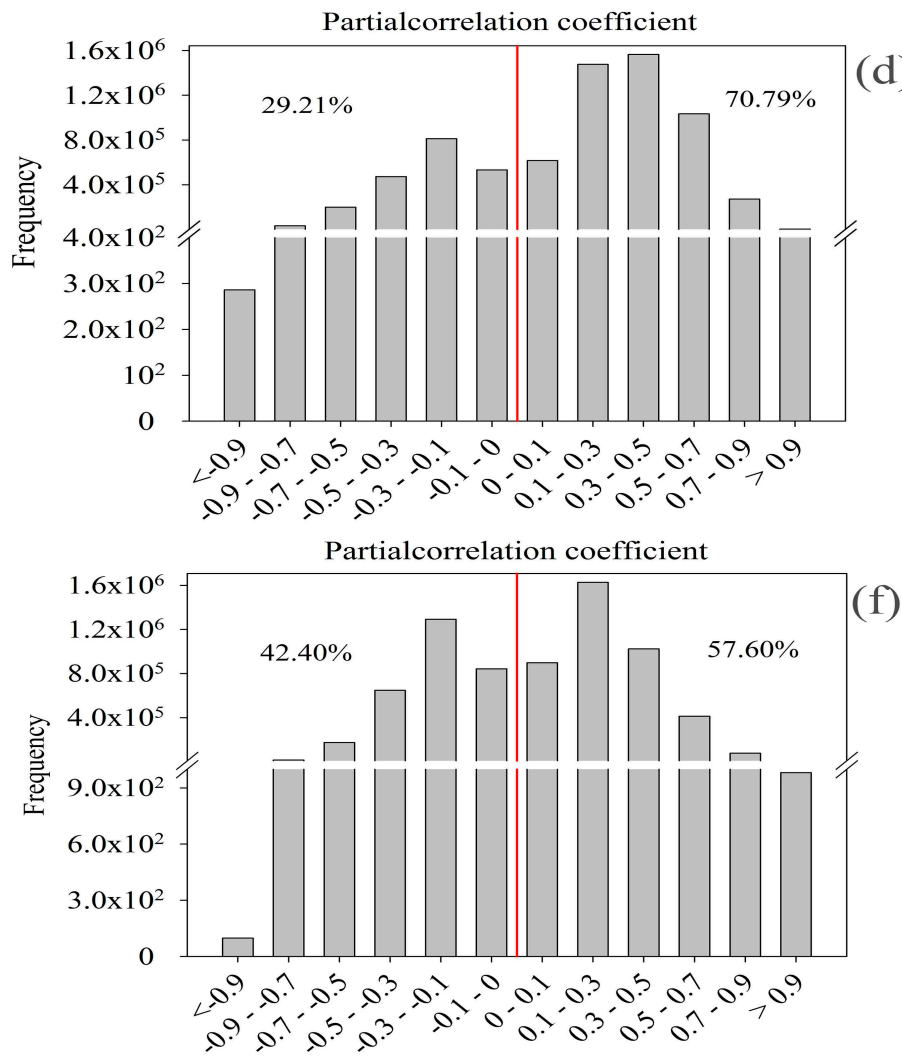

(f)

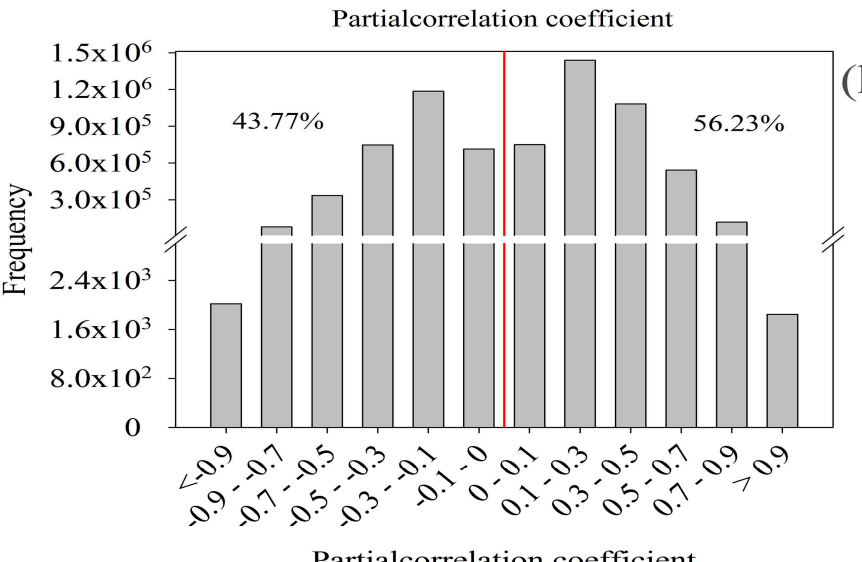

Figure 7. The partial correlation coefficients and corresponding frequency distribution between the NPP and temperature $(\mathbf{a}, \mathbf{b})$, precipitation $(\mathbf{c}, \mathbf{d})$, solar radiation $(\mathbf{e}, \mathbf{f})$ and LOS $(\mathbf{g}, \mathbf{h})$ in China from 2001 to 2014. The red lines in figures (b), (d), (f) and (h) represent boundary for negative relationship and positive relationship. 


\subsubsection{Structural Equation Models}

Our structural equation model (SEM) did not detect a relationship between temperature, precipitation and solar radiation, which indicates that there was a strong relationship among the climatic factors, LOS and NPP. In the SEM $\left(\chi^{2}=1.0138\right.$, d.f. $=5, p=0.9614$, AIC $=21.0138$, BIC $\left.=-1815\right)$, climatic factors explained a total of $23 \%$ of the variation in LOS, and temperature and solar radiation had a positive effect on LOS, while precipitation had the opposite effect (Figure 8). Moreover, the effect of climatic factors and LOS on NPP was 0.63 , and explained a total of $56 \%$ of the variation in NPP. Among the climatic factors, the direct effect of solar radiation on NPP was the largest $(0.31)$, followed by precipitation (0.25), and temperature (0.07).

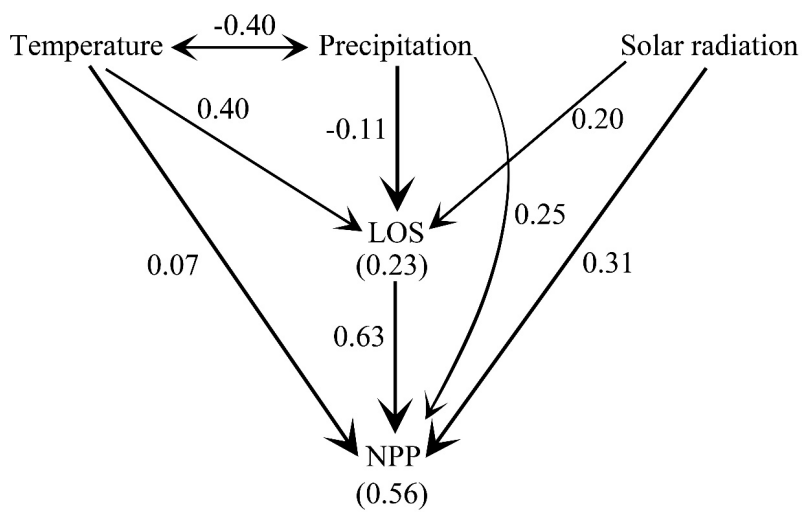

Figure 8. Structural equation model relating climatic factors, Length of Season (LOS) and Net Primary Productivity (NPP) in China. Single headed arrows indicate directional relationships, while double headed arrows indicate covariances. Numbers in brackets are $R^{2}$ values.

\section{Discussion}

\subsection{Uncertainties in NPP Estimates}

Net primary productivity (NPP), an indicator of the accumulation of atmospheric $\mathrm{CO}_{2}$ in terrestrial ecosystems, plays a crucial role in global change [54]. The accurate estimation of NPP is a crucial step for reliably quantifying carbon fluxes between the atmosphere and terrestrial ecosystems [31], especially for regions with different topography and climatic conditions. Although deficiency and biases exist in the MODIS derived NPP, the validation illustrated that the model applied by MODIS was superior to the Miami model and Thornthwaite Memorial model, with an increased $\mathrm{R}^{2}$ value and a decreased RMSE and MAE. The RMSE and MAE between the MODIS derived NPP and observations were only $0.19 \mathrm{~kg} \mathrm{C} \mathrm{m}^{-2}$ and $0.14 \mathrm{~kg} \mathrm{C} \mathrm{m}^{-2}$, respectively. This indicated that the MODIS derived NPP may be suitable for analysis with relatively low regional biases in China for the period of 2001-2014 to some extent despite coarse global climate data applied in MOD17. Additionally, it illustrated that the parameters input and algorithms may affect the results. For instance, the Miami model is one of the first global empirical models that only utilizes temperature or precipitation in the model [55], while the Thornthwaite Memorial model determines NPP for a particular location as the actual evapotranspiration functions [36]. The interactions among climatic factors and other influential factors such as vegetation types are not included in these two models [11]. Furthermore, there is no mechanism to account for changing vegetation density in the two models [56]. However, the model applied by MODIS incorporates biogeochemical principles in a mechanistic modeling environment and the vegetation feedback to climate conditions through changes in Leaf Area Index and absorbed radiation, and has the advantage of providing spatially continuous estimates with a consistent methodology, which is important for any large-scale studies [35]. It should be noted that NPP is not easy to measure and only 26 field sites were included in this study, which may cause biases due to the larger study area. In addition, heterogeneity, stand density, and pixel resolution may also 
affect validation results. Therefore, increased observation sites and an extended observation period has become essential for NPP estimation. Additionally, forest inventory data is the only data source that provides large-scale consistent productivity assessments [57]. Therefore, the application of forest inventory data rather than numerous field observed data in this study would be more preferable to validate the suitability of MODIS NPP in China, and more efforts should be made in the future. What is more, temporal analysis of match between models and observations based on a long time period were also a good choice for NPP estimates and comparison.

\subsection{Spatiotemporal Variation of NPP}

In general, all three NPP estimates showed similar spatial patterns, with mean annual NPP higher in the southeast and gradually decreasing towards the northwest (Figure 3 and Figure S2). This finding was consistent with previous studies [10-12,58]. This may have been due to the climatic gradient (e.g., temperature and precipitation) from the southeast to the northwest in China, which is more favorable for vegetation growth in southern China [11,59]. The lowest NPP value in northwest China and the Tibetan Plateau, which was consistent with References [10,11], may have resulted from low temperature and the absence of precipitation. In addition, vegetation type was also a key factor that affected NPP spatial distribution. In Southern China, the dominant vegetation type are evergreen forests (Figure S1) which have a higher productivity than that of the grassland and desert vegetation (Figure 4) distributed mostly in Northern China and the Tibetan Plateau. Productivity in the southeast Tibetan Plateau was higher than that of other areas in the Tibetan Plateau as demonstrated by our conclusion above.

The total amount of NPP increased at a rate of $0.009 \mathrm{Pg} \mathrm{C} \mathrm{a}^{-1}$ in China from 2001-2014, which was similar with Reference [10], who found a rate of $0.008 \mathrm{Pg} \mathrm{C} \mathrm{a}^{-1}$ in China from 1999-2010. The decreases in NPP over Southern China were more than offset by increases in NPP over Northern China and the Tibetan Plateau. The overall increased NPP could help to mitigate climate warming at regional scale and/or global scale to some extent. In terms of trend variation, a continually increasing trend of NPP in China from 2001-2014 was found, despite the occurrence of a turning point year which was similar with the previous finding in Reference [10]. This may be due to the fact that over the past three decades, the central government of China has decided to combat severe environmental degradation, including declining vegetation cover and expanding desertification [29]. To realize this goal, the Three North Shelter Forest System project, the Beijing-Tianjin Sand Source Control Program, and the Grain for Green Project [29] were implemented. Alternatively, as the turning point is related to ENSO events/cycles, it is necessary to validate this conclusion in the future.

At a regional scale, NPP trends in China showed a prominent geographical heterogeneity. The trends before and after the turning point year in Northern China and the Tibetan Plateau were all positive. In contrast, the trend in Southern China was the opposite, which may have been due to ecorestoration, forest/grassland protection, and reforestation in Northern China and the Tibetan Plateau after 2000 [29]. However, in Southern China, freezing low temperatures in early 2008, the severe drought in 2009 [31], and decreased solar radiation [12] may have all contributed to the decreasing NPP. Due to the physiological and/or local environmental conditions, the trend and turning point year among vegetation types were diverse.

\subsection{Diverse NPP Correlations with Climate Drivers and LOS}

Vegetation NPP is influenced by a variety of factors, and the primary one is climate-related. Temperature, precipitation, and solar radiation are the main climate drivers for vegetation growth [59], but the relationships vary with spatial scale. Nevertheless, limited efforts have been made to investigate the relative roles of different climate variables in the NPP [10]. Generally, temperature has been found to be positively correlated with the NPP at a national level, which is consistent with previous studies [10,60]. This response may in part be related to the increased activity of photosynthetic enzymes [61] and improved capacity for photosynthesis and growth [62]. However, the relationship 
between temperature and NPP in Northern China was negative. This may have resulted from higher temperatures leading to increased water scarcity caused by accelerated evaporation, which would work against vegetation growth, especially for arid and semi-arid areas in Northern China [49]. Additionally, the positive relationship between precipitation and NPP in Northern China illustrated this conclusion. Precipitation showed a positive correlation with NPP at both the national scale and regional scale, which may have occurred as more precipitation increases soil moisture, satisfying the water requirements for vegetation growth and productivity increase, especially in late spring and summer, which usually have higher temperatures and more evapotranspiration [63].

Little is known about the light-related physiological mechanisms that regulate NPP due to the difficulty in distinguishing the effects of day length (i.e., photoperiod) and light intensity [18], especially when studies are extended to consider their correlations with temperature and precipitation. Therefore, in this study, solar radiation was considered as an integrated surrogate for both day length and sunlight intensity [18] to investigate the effects of solar radiation on the NPP. A positive correlation was observed between the NPP and solar radiation at both the national and regional scales, except for a negative relationship which occurred in the Tibetan Plateau. Generally, increased solar radiation provides sufficient materials and energy for vegetation photosynthesis and solar radiation is typically accompanied by warmer temperatures and sufficient sunlight intensity, both of which can enhance photosynthetic capacity and promote vegetation NPP. The negative correlations between solar radiation and NPP in the Tibetan Plateau may be partly related to larger areas of melting seasonal snow and permafrost soils caused by abundant solar radiation, leading to higher soil moisture content and creating an anaerobic soil environment within the plant root zone, thus limiting vegetation growth [64]. Alternatively, increased solar radiation may enhance surface soil evaporation and limit water availability for herbaceous plants that have shallow root systems.

Vegetation phenology has long been regarded as an important factor that affects vegetation productivity. Consistent with previous studies in References [20,65], our results also indicated a positive relationship between the NPP and LOS at both national and regional levels. This suggests that an extension of LOS is one of the most important factors that affect plant productivity [66].

\subsection{Shortcomings and Uncertainties}

In this study, we used data from only 99 solar radiation stations, as meteorological stations in the Tibetan Plateau are scarce. The sparse distribution of climate data limited the detail and accuracy of the relationship between climatic factors and plant productivity. Therefore, the results are likely to be subject to some ambiguity.

Vegetation NPP is influenced by a variety of factors. In this study, only three climatic factors and LOS were considered. Although these factors have explained a total of $56 \%$ of the variation of NPP (Figure 8), other climate-related factors, such as sunshine duration, soil temperature, precipitation characteristics (e.g., effective precipitation, precipitation intensity), $\mathrm{CO}_{2}$ concentrations, $\mathrm{N}$ enrichment and deposition (e.g., policy and planning changes), should be considered in future studies [67]. Moreover, other phonological metrics (e.g., Start of Season, End of Season), species competition, and disturbances such as anthropogenic activities (irrigation, fertilization [68,69], harvest, land use/land cover change), wildfires, plant diseases, pests, floods, and droughts as well as the time-lag effect of the above-mentioned variables can vary by region [50], and should also be considered in future studies.

The results presented here indicate the complexity of vegetation NPP dynamics and the response or reaction strategy of vegetation to climate change during the study period. However, the trend for NPP before and after turning points were mostly non-significant despite all turning points being significant (except evergreen broadleaf forest) based on $\triangle \mathrm{AIC}$. This may be caused by a short time period, or a non-linear variation on NPP during the study period. Therefore, the conclusions mentioned above should be made with more caution, and more effort should be made to explore the NPP trends (e.g., non-linear trend) in the future to clarify the direction of dynamic NPP trends [70]. In addition, it is difficult to estimate future NPP dynamics using mathematical models (e.g., linear regression analysis) 
due to the nonlinear characteristics of NPP dynamics in a long time series, the uncertainty about future climate change, and the time-lag effect of NPP responses to climate change. To date, the Hurst exponent, which has been widely used in hydrology, climatology, economics, geology, and geochemistry, could be considered to predict the NPP variation. The results presented here (Figure S4) indicate that NPP in China will continue to increase based on the Hurst exponent. Unfortunately, this exponent characterizes trends based only on past and present environmental conditions, without considering future environmental change, especially in developing areas, or giving a time period for dynamic NPP trends. These limitations restrict our ability to predict and anticipate future NPP variation, the carbon cycle and its relationship with and response to climate change and human activity, and hence more effort must be made to predict future NPP variation.

\section{Conclusions}

In this study, the spatiotemporal patterns of NPP and its correlation with climatic factors as well as vegetation phenology during 2001-2014 in China were investigated, and the main conclusions can be summarized as follows:

1. Validation results showed that NPP derived from MODIS performed well in China's ecosystem compared with the other two models, with an increased $R^{2}$ value and a decreased RMSE and MAE. However, this conclusion should be made with caution due to few observed sites.

2. During the entire study period, annual NPP showed an increasing trend at the national scale. However, the increasing trends in NPP were not linear, with a slower rate after 2004. At a regional level, annual NPP displayed an increasing trend, despite the occurrence of a turning point year in Northern China and the Tibetan Plateau. However, the NPP in Southern China decreased during the whole study period, which can mainly be explained by climate change as well as fierce anthropogenic activities.

3. Generally, climatic factors and LOS were positively correlated with NPP, and the direct effect of solar radiation on NPP was the largest compared with temperature and precipitation. Due to local climate conditions, the relationship between NPP and climatic factors were diverse at a regional scale.

Supplementary Materials: The following are available online at www.mdpi.com/1999-4907/8/10/361/s1, Table S1: Sites information of the field Net primary productivity (NPP) data used in this study; Figure S1: Vegetation types (DNF, deciduous needle-leaf forest; ENF, evergreen needle-leaf forest; EBF, evergreen broadleaf forest; DBF, deciduous broadleaf forest; and GM, grassland and meadow) as well as three sub-region divisions (a), and provinces distribution (b) in China; Figure S2: Distribution of meteorological stations across China, red points represent stations for temperature and precipitation, and black triangles represent stations for solar radiation; Figure S3: Spatial distribution of Turing Point (TP) years (a) and corresponding $\triangle \mathrm{AIC}$ values (b) of the NPP in China for the period 2001-2014; Figure S4: Spatial distribution of the Hurst exponent in China from 2001 to 2014.

Acknowledgments: This study is supported by the National Natural Science Foundation of China (Grant No. 41431178), the Natural Science Foundation of Guangdong Province, China (Grant No. 2016A030311016), the Innovation Project of Guangdong Province Water Resources Department (Grant No. 2015-02) and the Central Fund Supporting Nonprofit Scientific Institutes for Basic Research and Development (PM-zx021-201407-007).

Author Contributions: Xinchang Zhang and Xijun Yu outlined the research topic, assisted with manuscript writing, and coordinated the revision activities. Jian Yang and Zhaohui Luo performed data collection, data analysis, the interpretation of results, manuscript writing, and coordinated the revision activities.

Conflicts of Interest: The authors declare no conflict of interest.

\section{References}

1. Haberl, H.; Erb, K.H.; Krausmann, F.; Gaube, V.; Bondeau, A.; Plutzar, C.; Gingrich, S.; Lucht, W.; Fischer-Kowalski, M. Quantifying and mapping the human appropriation of net primary production in earth's terrestrial ecosystems. Proc. Natl. Acad. Sci. USA 2007, 104, 12942-12947. [CrossRef] [PubMed] 
2. Allen, C.D.; Macalady, A.K.; Chenchouni, H.; Bachelet, D.; McDowell, N.; Vennetier, M.; Kitzberger, T.; Rigling, A.; Breshears, D.D.; Hogg, E.H.; et al. A global overview of drought and heat-induced tree mortality reveals emerging climate change risks for forests. For. Ecol. Manag. 2010, 259, 660-684. [CrossRef]

3. Luo, Z.; Tian, D.; Ning, C.; Yan, W.; Xiang, W.; Peng, C. Roles of koelreuteria bipinnata as a suitable accumulator tree species in remediating $\mathrm{Mn}, \mathrm{Zn}, \mathrm{Pb}$, and $\mathrm{Cd}$ pollution on $\mathrm{Mn}$ mining wastelands in southern china. Environ. Earth Sci. 2015, 74, 4549-4559. [CrossRef]

4. Pimm, S.L.; Raven, P. Biodiversity. Extinction by numbers. Nature 2000, 403, 843-845. [CrossRef] [PubMed]

5. Sala, O.E.; Chapin, F.S.; Armesto, J.J.; Berlow, E.; Bloomfield, J.; Dirzo, R.; Huber-Sanwald, E.; Huenneke, L.F.; Jackson, R.B.; Kinzig, A. Global biodiversity scenarios for the year 2100. Science 2000, 287, 1770-1774. [CrossRef] [PubMed]

6. Houghton, R.A.; Hackler, J.L.; Lawrence, K.T. The U.S. Carbon budget: Contributions from land-use change. Science 1999, 285, 574-578. [CrossRef] [PubMed]

7. Twine, T.E.; Kucharik, C.J. Climate impacts on net primary productivity trends in natural and managed ecosystems of the central and eastern united states. Agric. For. Meteorol. 2009, 149, 2143-2161. [CrossRef]

8. Burnham, K.P.; Anderson, D.R. Model Selection and Multimodel Inference: A Practical Information-Theoretic Approach; Springer Science \& Business Media: Berlin, Germany, 2003.

9. Sisay, K.; Thurnher, C.; Belay, B.; Lindner, G.; Hasenauer, H. Volume and carbon estimates for the forest area of the amhara region in northwestern ethiopia. Forests 2017, 8, 122. [CrossRef]

10. Liang, W.; Yang, Y.; Fan, D.; Guan, H.; Zhang, T.; Long, D.; Zhou, Y.; Bai, D. Analysis of spatial and temporal patterns of net primary production and their climate controls in china from 1982 to 2010. Agric. For. Meteorol. 2015, 204, 22-36. [CrossRef]

11. Zhang, M.; Lal, R.; Zhao, Y.; Jiang, W.; Chen, Q. Estimating net primary production of natural grassland and its spatio-temporal distribution in china. Sci. Total Environ. 2016, 553, 184-195. [CrossRef] [PubMed]

12. Wang, J.; Dong, J.; Yi, Y.; Lu, G.; Oyler, J.; Smith, W.; Zhao, M.; Liu, J.; Running, S. Decreasing net primary production due to drought and slight decreases in solar radiation in China from 2000 to 2012. J. Geophys. Res. Biogeosci. 2017, 122, 261-278. [CrossRef]

13. Pan, Y.; Wu, J.; Xu, Z. Analysis of the tradeoffs between provisioning and regulating services from the perspective of varied share of net primary production in an alpine grassland ecosystem. Ecol. Complex. 2014, 17, 79-86. [CrossRef]

14. Brouwers, N.C.; Coops, N.C. Decreasing net primary production in forest and shrub vegetation across southwest australia. Ecol. Indic. 2016, 66, 10-19. [CrossRef]

15. Zhao, M.; Heinsch, F.A.; Nemani, R.R.; Running, S.W. Improvements of the modis terrestrial gross and net primary production global data set. Remote Sens. Environ. 2005, 95, 164-176. [CrossRef]

16. The Modis Land Cover and Land Cover Dynamics Products. Available online: https://xue.glgoo.net/ scholar?cluster $=16597624334725163726 \& h l=z h-C N \& a s \_s d t=2005 \& s c i o d t=0,5$ (accessed on 22 June 2017).

17. Gu, F.; Zhang, Y.; Huang, M.; Tao, B.; Guo, R.; Yan, C. Effects of climate warming on net primary productivity in China during 1961-2010. Ecol. Evol. 2017. [CrossRef] [PubMed]

18. Calle, Z.; Schlumpberger, B.O.; Piedrahita, L.; Leftin, A.; Hammer, S.A.; Tye, A.; Borchert, R. Seasonal variation in daily insolation induces synchronous bud break and flowering in the tropics. Trees 2010, 24, 865-877. [CrossRef]

19. Luo, Z.; Yu, S. Spatiotemporal variability of land surface phenology in china from 2001-2014. Remote Sens. 2017, 9, 65. [CrossRef]

20. Wu, C.; Hou, X.; Peng, D.; Gonsamo, A.; Xu, S. Land surface phenology of china's temperate ecosystems over 1999-2013: Spatial-temporal patterns, interaction effects, covariation with climate and implications for productivity. Agric. For. Meteorol. 2016, 216, 177-187. [CrossRef]

21. Peng, J.; Liu, Z.; Liu, Y.; Wu, J.; Han, Y. Trend analysis of vegetation dynamics in qinghai-tibet plateau using hurst exponent. Ecol. Indic. 2012, 14, 28-39. [CrossRef]

22. Zhang, Y.; Gao, J.; Liu, L.; Wang, Z.; Ding, M.; Yang, X. Ndvi-based vegetation changes and their responses to climate change from 1982 to 2011: A case study in the koshi river basin in the middle himalayas. Glob. Planet. Chang. 2013, 108, 139-148. [CrossRef]

23. Wen, Z.; Wu, S.; Chen, J.; Lü, M. Ndvi indicated long-term interannual changes in vegetation activities and their responses to climatic and anthropogenic factors in the three gorges reservoir region, China. Sci. Total Environ. 2017, 574, 947-959. [CrossRef] [PubMed] 
24. Piao, S.; Ciais, P.; Lomas, M.; Beer, C.; Liu, H.; Fang, J.; Friedlingstein, P.; Huang, Y.; Muraoka, H.; Son, Y. Contribution of climate change and rising $\mathrm{CO}_{2}$ to terrestrial carbon balance in east asia: A multi-model analysis. Glob. Planet. Chang. 2011, 75, 133-142. [CrossRef]

25. Mu, Q.; Zhao, M.; Running, S.W.; Liu, M.; Tian, H. Contribution of increasing $\mathrm{CO}_{2}$ and climate change to the carbon cycle in China's ecosystems. J. Geophys. Res. Biogeosci. 2008. [CrossRef]

26. Xu, W.C.; Wang, W.; Ma, J.S.; Yang, X. The characteristics, causes of formation and climatic impact of the 1997-1998 El Niño event. Donghai Mar. Sci. 2004, 22, 1-8.

27. Lu, E.; Luo, Y.; Zhang, R.; Wu, Q.; Liu, L. Regional atmospheric anomalies responsible for the 2009-2010 severe drought in china. J. Geophys. Res. Atmos. 2011. [CrossRef]

28. Liu, J.; Zhang, Q.; Hu, Y. Regional differences of China's urban expansion from late 20th to early 21st century based on remote sensing information. Chin. Geogr. Sci. 2012, 22, 1-14. [CrossRef]

29. Duan, H.; Yan, C.; Tsunekawa, A.; Song, X.; Li, S.; Xie, J. Assessing vegetation dynamics in the three-north shelter forest region of china using avhrr ndvi data. Environ. Earth Sci. 2011, 64, 1011-1020. [CrossRef]

30. Sasai, T.; Saigusa, N.; Nasahara, K.N.; Ito, A.; Hashimoto, H.; Nemani, R.; Hirata, R.; Ichii, K.; Takagi, K.; Saitoh, T.M. Satellite-driven estimation of terrestrial carbon flux over far east asia with 1-km grid resolution. Remote Sens. Environ. 2011, 115, 1758-1771. [CrossRef]

31. Liu, Y.; Ju, W.; He, H.; Wang, S.; Sun, R.; Zhang, Y. Changes of net primary productivity in china during recent 11 years detected using an ecological model driven by modis data. Front. Earth Sci. 2013, 7, 112-127. [CrossRef]

32. Liu, F.H.; Chen, X.; Chen, X.W.; Song, S. Relationship between temperature change and in climate boundary and summer precipitation over the huaihe river basin. Clim. Environ. Res. 2010, 15, 169-178.

33. Wang, H.; Dai, J.; Zheng, J.; Ge, Q. Temperature sensitivity of plant phenology in temperate and subtropical regions of china from 1850 to 2009. Int. J. Climatol. 2015, 35, 913-922. [CrossRef]

34. Shen, M.; Tang, Y.; Chen, J.; Zhu, X.; Zheng, Y. Influences of temperature and precipitation before the growing season on spring phenology in grasslands of the central and eastern qinghai-tibetan plateau. Agric. For. Meteorol. 2011, 151, 1711-1722. [CrossRef]

35. Zhao, M.; Running, S.W. Drought-induced reduction in global terrestrial net primary production from 2000 through 2009. Science 2010, 329, 940-943. [CrossRef] [PubMed]

36. Lieth, H. Modeling the primary productivity of the world. In Primary Productivity of the Biosphere; Lieth, H., Whittaker, R.H., Eds.; Springer: Berlin/Heidelberg, Germany, 1975; pp. 237-263.

37. ChinaFLUX Sites. Available online: http://www.chinaflux.org/ (accessed on 10 September 2017).

38. Baldocchi, D.; Falge, E.; Gu, L.; Olson, R.; Hollinger, D.; Running, S.; Anthoni, P.; Bernhofer, C.; Davis, K.; Evans, R.; et al. Fluxnet: A new tool to study the temporal and spatial variability of ecosystem-scale carbon dioxide, water vapor, and energy flux densities. Bull. Am. Meteorol. Soc. 2001, 82, 2415-2434. [CrossRef]

39. China Meteorological Data Sharing Service System. Available online: http://cdc.cma.gov.cn/ (accessed on 6 June 2016).

40. Xu, L.; Chen, X. Regional unified model-based leaf unfolding prediction from 1960 to 2009 across northern china. Glob. Chang. Biol. 2013, 19, 1275-1284. [CrossRef] [PubMed]

41. Peng, S.; Chen, A.; Xu, L.; Cao, C.; Fang, J.; Myneni, R.B.; Pinzon, J.E.; Tucker, C.J.; Piao, S. Recent change of vegetation growth trend in China. Environ. Res. Lett. 2011. [CrossRef]

42. Zhu, W.; Tian, H.; Xu, X.; Pan, Y.; Chen, G.; Lin, W. Extension of the growing season due to delayed autumn over mid and high latitudes in north america during 1982-2006. Glob. Ecol. Biogeogr. 2012, 21, 260-271. [CrossRef]

43. Jönsson, P.; Eklundh, L. Timesat 3.0 Software Manual; Department of Earth and Ecosystem Sciences, Lund University and Center for Technology Studies, Malmö University: Malmö, Sweden, 2010.

44. Sun, L.; Wei, J.; Duan, D.H.; Guo, Y.M.; Yang, D.X.; Jia, C.; Mi, X.T. Impact of land-use and land-cover change on urban air quality in representative cities of china. J. Atmos. Sol.-Terr. Phys. 2016, 142, 43-54. [CrossRef]

45. Wei, Y.-X.; Wang, L.-W. Progress in research on land cover products of modis. Spectrosc. Spectr. Anal. 2010, $30,1848-1852$.

46. Neeti, N.; Eastman, J.R. A contextual mann-kendall approach for the assessment of trend significance in image time series. Trans. GIS 2011, 15, 599-611. [CrossRef] 
47. Wang, C.; Guo, H.; Zhang, L.; Liu, S.; Qiu, Y.; Sun, Z. Assessing phenological change and climatic control of alpine grasslands in the tibetan plateau with modis time series. Int. J. Biometeorol. 2015, 59, 11-23. [CrossRef] [PubMed]

48. Zhou, J.; Cai, W.; Qin, Y.; Lai, L.; Guan, T.; Zhang, X.; Jiang, L.; Du, H.; Yang, D.; Cong, Z. Alpine vegetation phenology dynamic over 16 years and its covariation with climate in a semi-arid region of china. Sci. Total Environ. 2016, 572, 119-128. [CrossRef] [PubMed]

49. Xu, H.-J.; Wang, X.-P.; Yang, T.-B. Trend shifts in satellite-derived vegetation growth in central eurasia, 1982-2013. Sci. Total Environ. 2017, 579, 1658-1674. [CrossRef] [PubMed]

50. Xu, G.; Zhang, H.; Chen, B.; Zhang, H.; Innes, J.L.; Wang, G.; Yan, J.; Zheng, Y.; Zhu, Z.; Myneni, R.B. Changes in vegetation growth dynamics and relations with climate over China's landmass from 1982 to 2011. Remote Sens. 2014, 6, 3263-3283. [CrossRef]

51. Akaike, H. A new look at the statistical model identification. IEEE Trans. Autom. Control 1974, 19, 716-723. [CrossRef]

52. Shen, Y.; Yu, S.; Lian, J.; Shen, H.; Cao, H.; Lu, H.; Ye, W. Tree aboveground carbon storage correlates with environmental gradients and functional diversity in a tropical forest. Sci. Rep. 2016, 6, 25304. [CrossRef] [PubMed]

53. Fox, J. Teacher's corner: Structural equation modeling with the sem package in R. Struct. Equ. Model. Multidiscip. J. 2006, 13, 465-486. [CrossRef]

54. Roxburgh, S.H.; Berry, S.L.; Buckley, T.N.; Barnes, B.; Roderick, M.L. What is NPP? Inconsistent accounting of respiratory fluxes in the definition of net primary production. Funct. Ecol. 2005, 19, 378-382. [CrossRef]

55. Zaks, D.P.M.; Ramankutty, N.; Barford, C.C.; Foley, J.A. From miami to madison: Investigating the relationship between climate and terrestrial net primary production. Glob. Biogeochem. Cycles 2007. [CrossRef]

56. Adams, B.; White, A.; Lenton, T.M. An analysis of some diverse approaches to modelling terrestrial net primary productivity. Ecol. Model. 2004, 177, 353-391. [CrossRef]

57. Tomppo, E.; Gschwantner, T.; Lawrence, M.; McRoberts, R. National Forest Inventories: Pathways for Common Reporting; Springer: Berlin, Germany, 2010.

58. Piao, S.; Fang, J.; Zhou, L.; Zhu, B.; Tan, K.; Tao, S. Changes in vegetation net primary productivity from 1982 to 1999 in china. Glob. Biogeochem. Cycles 2005, 19, 1-16. [CrossRef]

59. Richardson, A.D.; Keenan, T.F.; Migliavacca, M.; Ryu, Y.; Sonnentag, O.; Toomey, M. Climate change, phenology, and phenological control of vegetation feedbacks to the climate system. Agric. For. Meteorol. 2013, 169, 156-173. [CrossRef]

60. Yu, G.-R.; Zhu, X.-J.; Fu, Y.-L.; He, H.-L.; Wang, Q.-F.; Wen, X.-F.; Li, X.-R.; Zhang, L.-M.; Zhang, L.; Su, W.; et al. Spatial patterns and climate drivers of carbon fluxes in terrestrial ecosystems of China. Glob. Chang. Biol. 2013, 19, 798-810. [CrossRef] [PubMed]

61. Shi, C.; Sun, G.; Zhang, H.; Xiao, B.; Ze, B.; Zhang, N.; Wu, N. Effects of warming on chlorophyll degradation and carbohydrate accumulation of alpine herbaceous species during plant senescence on the tibetan plateau. PLoS ONE 2014, 9, e107874. [CrossRef] [PubMed]

62. Liu, Q.; Fu, Y.H.; Zhu, Z.; Liu, Y.; Liu, Z.; Huang, M.; Janssens, I.A.; Piao, S. Delayed autumn phenology in the northern hemisphere is related to change in both climate and spring phenology. Glob. Chang. Biol. 2016, 22, 3702-3711. [CrossRef] [PubMed]

63. Ibrahim, Y.; Balzter, H.; Kaduk, J.; Tucker, C. Land degradation assessment using residual trend analysis of gimms ndvi3g, soil moisture and rainfall in sub-saharan west africa from 1982 to 2012. Remote Sens. 2015, 7, 5471-5494. [CrossRef]

64. Yang, Y.; Guan, H.; Shen, M.; Liang, W.; Jiang, L. Changes in autumn vegetation dormancy onset date and the climate controls across temperate ecosystems in china from 1982 to 2010. Glob. Chang. Biol. 2015, 21, 652-665. [CrossRef] [PubMed]

65. Dragoni, D.; Schmid, H.P.; Wayson, C.A.; Potter, H.; Grimmond, C.S.B.; Randolph, J.C. Evidence of increased net ecosystem productivity associated with a longer vegetated season in a deciduous forest in south-central indiana, USA. Glob. Chang. Biol. 2011, 17, 886-897. [CrossRef]

66. Piao, S.; Friedlingstein, P.; Ciais, P.; Viovy, N.; Demarty, J. Growing season extension and its impact on terrestrial carbon cycle in the northern hemisphere over the past 2 decades. Glob. Biogeochem. Cycles 2007. [CrossRef] 
67. Suepa, T.; Qi, J.; Lawawirojwong, S.; Messina, J.P. Understanding spatio-temporal variation of vegetation phenology and rainfall seasonality in the monsoon southeast asia. Environ. Res. 2016, 147, 621-629. [CrossRef] [PubMed]

68. He, L.; Chen, J.M.; Liu, J.; Bélair, S.; Luo, X. Assessment of smap soil moisture for global simulation of gross primary production. J. Geophys. Res. Biogeosci. 2017, 122, 1549-1563. [CrossRef]

69. Liu, X.; Zhang, Y.; Han, W.; Tang, A.; Shen, J.; Cui, Z.; Vitousek, P.; Erisman, J.W.; Goulding, K.; Christie, P.; et al. Enhanced nitrogen deposition over china. Nature 2013, 494, 459-462. [CrossRef] [PubMed]

70. Li, S.C.; Zhao, Z.Q.; Gao, Y.; Wang, Y.L. Determining the predictability and the spatial pattern of urban vegetation using recurrence quantification analysis: A case study of shenzhen city. Geogr. Res. 2008, 27, 1243-1252.

(C) 2017 by the authors. Licensee MDPI, Basel, Switzerland. This article is an open access article distributed under the terms and conditions of the Creative Commons Attribution (CC BY) license (http:/ / creativecommons.org/licenses/by/4.0/). 